\title{
Equilibrium Study for Reactive Extraction of Caproic Acid in Mibk and Xylene
}

\author{
Kailas L. Wasewar*, Diwakar Z. Shende \\ Department of Chemical Engineering, Visvesvaraya National Institute of Technology, Nagpur, India \\ E-mail: $k$ wasewar@rediffmail.com \\ Received November 19, 2010; revised June 8, 2011; accepted June 20, 2011
}

\begin{abstract}
The recovery of caproic acid from the aqueous stream is of practical relevance due to its market value and the stringent environmental standards. The profound success of reactive extraction has been noted in the recovery of carboxylic acids from dilute solutions. In present paper, equilibrium of caproic acid with aliquat-336, a quaternary amine compound, in xylene and Methyl Isobutyl Ketone (MIBK) has been studied. Equilibrium parameters such as distribution coefficients, loading ratio, degree of extraction and equilibrium complexation constants have been presented. The data obtained is useful in understanding the equilibrium characteristics and efficient design of the recovery process of caproic acid by reactive extraction.
\end{abstract}

Keywords: Caproic Acid, Reactive Extraction, Aliquat-336, Xylene, MIBK

\section{Introduction}

The recovery of caproic acid from an aqueous stream is of considerable commercial importance from an environmental point of view. Caproic acid impart finite chemical oxygen demand (COD) and biochemical oxygen demand (BOD) to the aqueous waste [1]. Caproic acid is formed during the air oxidation of cyclohexane in the manufacture of cyclohexanone/nol in a caprolactam plant. Caproic acid is a by-product and conventionally separated from the reaction mixture by extraction with an aqueous caustic to form water-soluble, sodium salt of respective acids [2]. The resulting aqueous stream (after extraction with aqueous caustic) is then neutralized with $\mathrm{H}_{2} \mathrm{SO}_{4}$ to liberate the caproic acid. Thus, this method of recovery is expensive and unfriendly to the environment as it consumes sodium hydroxide and sulphuric acid and also produces a large quantity of sodium sulphate sludge as solid waste.

Caproic acid is a carboxylic acid and it can be produced by the fermentation route [3]. Carboxylic acids are promising intermediates, because the oxygen of the biomass is placed in a form that is useful for further reaction with many other products. Low concentrations of carboxylic acids $(<10 \%)$ are achieved in fermentations. Chemical reaction combined with extraction can be considered as an alternative to the conventional calcium salt precipitation techniques for the recovery of carboxylic acids from aqueous stream. Reactive extraction with specified extractant giving a higher distribution coefficient has been proposed as a promising technique for the recovery of carboxylic and hydroxycarboxylic acids $[4,5]$. Reactive liquid-liquid extraction has the advantage that caproic acid can be removed easily from aquesous stream. Further, the caproic acid can be re-extracted and the extractant recycled to the process. When selecting an extractant, along with other considerations such as price, availability, ease of regeneration, very high distribution coefficients, and low toxicity, one must ensure that the extractant is environment friendly [1]. In other words, the extractant should have as low solubility in water as possible, so that it does not add substantially to COD of the aqueous raffinate. Methyltricaprylammonium chloride (Aliquat-336) is one such solvent that process environmental engineers can use in their process [6-8].

Long-chain aliphatic amines are effective extractants for the separation of carboxylic acids from dilute solution [6-8]. The amines are been favored because of lower cost and generally higher distribution coefficient. Among different amines, extraction with primary amines is characterized by a large mutual solubility of the aqueous and organic phase. The secondary amines have the highest reported distribution coefficient, but tend to form amides is the downstream regeneration by distillation. The quaternary amines extract carboxylic acids at both acidic and basic $\mathrm{pH}$ via an anoin exchange mechanism [7]. Conse- 
quently, quaternary and tertiary amines are the most attractive for extractive fermentation on the on the basis of their low aqueous solubility and intermediate basicity, the latter providing for reasonable extracting power alongwith the possibility of stripping. The specific chemical interactions between the amines and the acid molecules to form acid-amine complexes in the extractant phase allow more acid to be extracted from the aqueous phase [8]. Generally, the amine extractants are dissolved in a diluent such as a ketone, an alcohol, hydrocarbons, etc., that is an organic solvent that dilute the extractant to the desired concentration and controls the viscosity and density of the solvent phase. Diluent is usually added along with the extractant to enhance its physical properties by providing general solvation and affect the extraction power of the extractant by providing specific interaction. The diluent may consists of one or more components, inert or active. Various active polar and proton or electron donating diluents (halogenated aliphatic/aromatic hydrocarbons, ketones, nitrobenzenes, higher alcohols), enhance the extraction. On the other hand, inert diluents (long chain paraffins, benzene etc.), limit the solvent capacity. The three important variables which can influence the equilibrium extraction characteristics of the system are: the nature of the acid extracted, the concentration of the extractant, and the type of diluent [9]. Wasewar and his group have extensively worked on reactive extraction of various carboxylic acids [10-19].

Wang et al. [20] suggested the use and importance of liquid-liquid extraction for recovery of caproic acid using trialkylphosphine oxide (TRPO). Equilibria of aqueous solutions of caproic acid with TRPO in kerosene were investigated. An extraction equilibrium model was used to describe the experimental data.

Tributylphosphate (TBP) was used to separate caproic acid from an aqueous waste stream at $\mathrm{pH} 2$ - 2.5 (Ingale, 1996) [21]. The distribution coefficient $K_{D}$ was measured for the extraction of caproic acid from aqueous waste stream and also the effect of presence of salts such as sodium sulphate and sodium chloride was studied.

Kencaly et al. [3], used a novel method of caproic acid synthesis. They used ruminal bacteria Ruminococcus flavefaciens and non-ruminal bacterium Clostridium Ckluyveri which are grown together on cellulose and ethanol. Succinate and acetate produced by the cellulolytic organisms were converted to butyrate and caproate only when the culture medium was supplemented with ethanol. They suggested the use of ruminal and non ruminal bacteria, which are naturally produced and act as an inexpensive starting material, thereby preventing high cost of production. The method also paves the way for extraction from waste streams which have low concentrations of caproic acid, using Ckluyveri.
Senol [22] studied the liquid-liquid equilibrium [water + caproic acid + 1-octanol] at $293.15 \mathrm{~K}$ and $101.3 \mathrm{kPa} \pm$ $0.7 \mathrm{kPa}$. A log-basis approach SERLAS (solvation energy relation for liquid associated system) has been proposed to estimate the properties and liquid-liquid equilibria (LLE) of tertiary associated systems containing proton-donating and -accepting components capable of a physical interaction through hydrogen bonding. The reliability of the model has been analyzed against the LLE data with respect to the distribution ratio and separation factor.

A lot of work on the reactive extraction of different carboxylic acids using tertiary and quaternary amine has been done but very little work on caproic acid extraction can be found. In view of this, attempts were made to study the extraction of caproic acid using aliquat-336 in MIBK and xylene. The data on the distribution coefficient, equilibrium complexation constant, loading and extraction efficiency were presented. The distribution of caproic acid between water and aliquat-336 dissolved in various diluents, and a comparison with the extraction capacity of pure diluent alone were studied at isothermal conditions.

\section{Theory}

The quaternary ammonium chloride (Aliquat 336) extracts both the dissociated and undissociated forms of acids [7]. For the extraction of caproic acid (HA) by Aliquat $336\left(\mathrm{R}_{4} \mathrm{~N}^{+} \mathrm{Cl}^{-}\right)$with chemical interaction (Figure 1), the distribution coefficient of caproate ions $K_{\mathrm{D}}\left(\mathrm{A}^{-}\right)$ can be written as:

$$
K_{\mathrm{D}_{\left(\mathrm{A}^{-}\right)}}=\frac{\left[\mathrm{R}_{4} \mathrm{~N}^{+} \mathrm{Cl}^{-}: \mathrm{A}^{-}\right]_{\text {org }}}{[\mathrm{HA}]_{\mathrm{aq}}+\left[\mathrm{A}^{-}\right]_{\mathrm{aq}}}
$$

For extraction of the undissociated molecules, distribution coefficient of undissociated acid $K_{\mathrm{D}(\mathrm{HA})}$ can be defined as

$$
K_{\mathrm{D}(\mathrm{HA})}=\frac{\left[\mathrm{R}_{4} \mathrm{~N}^{+} \mathrm{Cl}^{-}: \mathrm{HA}\right]_{\mathrm{org}}}{[\mathrm{HA}]_{\mathrm{aq}}+\left[\mathrm{A}^{-}\right]_{\mathrm{aq}}}
$$

The overall distribution coefficient $\left(K_{\mathrm{D}}\right)$ can be represented as:

$$
K_{\mathrm{D}}=K_{\mathrm{D},\left(\mathrm{A}^{-}\right)}+K_{\mathrm{D}(\mathrm{HA})}
$$

Kyuchoukov et al. [23] studied the extraction of lactic acid with Aliquat 336 and found that at low $\mathrm{pH}$ values and low acid concentration the proportion of the undissociated molecule removed by the extractant was larger than the proportion of the extracted anions, but with increasing $\mathrm{pH}$, the ratio changes. Thus the concentration of 
undissociated acid is a function of the $\mathrm{pH}$ of the aqueous phase. Since the $\mathrm{pH}$ in present study is between $2.403-$ 3.084 , it can be assumed that only the undissociated acid was involved in extraction. The extraction of the undissociated molecules of caproic acid by chemical interaction thus can be represented as:

$$
\left[\mathrm{R}_{4} \mathrm{~N}^{+} \mathrm{Cl}^{-}\right]_{\text {org }}+[\mathrm{HA}]_{\mathrm{aq}} \leftrightarrow\left[\mathrm{R}_{4} \mathrm{~N}^{+} \mathrm{Cl}^{-}: \mathrm{HA}\right]_{\text {org }}
$$

with the extraction constant $\left(K_{\mathrm{E}}\right)$

$$
\begin{aligned}
K_{\mathrm{E}} & =\frac{\left[\mathrm{R}_{4} \mathrm{~N}^{+} \mathrm{Cl}^{-}: \mathrm{HA}\right]_{\text {org }}}{[\mathrm{HA}]\left[\mathrm{R}_{4} \mathrm{~N}^{+} \mathrm{Cl}^{-}\right]_{\text {org }}} \\
& =\frac{\left[\mathrm{R}_{4} \mathrm{~N}^{+} \mathrm{Cl}^{-}: \mathrm{HA}\right]_{\text {org }}\left(K_{\mathrm{a}}+\left[\mathrm{H}^{+}\right]\right)}{\left[\mathrm{H}^{+}\right]\left\{[\mathrm{HA}]+\left[\mathrm{A}^{-}\right]\right\}\left[\mathrm{R}_{4} \mathrm{~N}^{+} \mathrm{Cl}^{-}\right]_{\text {org }}} \\
& =\frac{K_{\mathrm{D}(\mathrm{HA})}}{\left[\mathrm{R}_{4} \mathrm{~N}^{+} \mathrm{Cl}^{-}\right]_{\text {org }}(1-\alpha)}
\end{aligned}
$$

$K_{\mathrm{a}}$ in Equation (5) is the dissociation constant of the acid and $\alpha=K_{a} /\left(K_{a}+\left[H^{+}\right]\right)$represents the part of dissociated form of acid. Rearranging Equation (5) we get:

$$
K_{\mathrm{D}(\mathrm{HA})}=\frac{\left[\mathrm{R}_{4} \mathrm{~N}^{+} \mathrm{Cl}^{-}: \mathrm{HA}\right]_{\mathrm{org}}}{\left([\mathrm{HA}]+\left[\mathrm{A}^{-}\right]\right)}=K_{\mathrm{E}}(1-\alpha)\left[\mathrm{R}_{4} \mathrm{~N}^{+} \mathrm{Cl}^{-}\right]_{\mathrm{org}}
$$

$$
\frac{K_{\mathrm{D}(\mathrm{HA})}}{(1-\alpha)}=K_{\mathrm{E}}\left[\mathrm{R}_{4} \mathrm{~N}^{+} \mathrm{Cl}^{-}\right]_{\text {org }}
$$

The distribution coefficient and equilibrium extraction coefficient of undissociated molecules can be determined under the condition that $\alpha=0$ i.e. mineral acid must be added, but in this way, the extraction system changes and $K_{\mathrm{D}(\mathrm{HA})}$ will not be the same as in the absence of mineral acid.

Taking log of Equation (7), we get:

$$
\log K_{\mathrm{D}}=\log K_{\mathrm{E}}+\log \left[\mathrm{R}_{4} \mathrm{~N}^{+} \mathrm{Cl}^{-}\right]_{\text {org }}
$$

The plot of $\log K_{\mathrm{D}}$ against $\log \left[\mathrm{R}_{4} \mathrm{~N}^{+} \mathrm{Cl}^{-}\right]_{\text {org }}$ should provide a straight line with the intercept of $\log K_{\mathrm{E}}$, from which the equilibrium complexation constant can be obtained. From the above equation it can be seen that the distribution coefficient depends on the free extractant concentration in the organic phase. The equilibrium concentration of free extractant can be represented as:

$$
\left[\mathrm{R}_{4} \mathrm{~N}^{+} \mathrm{Cl}^{-}\right]_{\text {org }}=\left[\mathrm{R}_{4} \mathrm{~N}^{+} \mathrm{Cl}^{-}\right]_{\text {org }}^{o}-\left[\mathrm{R}_{4} \mathrm{~N}^{+} \mathrm{Cl}^{-}: \mathrm{HA}\right]_{\text {org }}
$$

where superscript " $O$ " refers to initial concentration.

Degree of extraction $(E \%)$ is defined as the ratio of caproic acid concentration in organic phase to the sum of acid concentration in organic and aqueous phase and is defined in term of $K_{\mathrm{D}}$ as

$$
E \%=\frac{K_{\mathrm{D}} \times 100}{1+K_{\mathrm{D}}}
$$

\section{Experimental}

\subsection{Materials}

Aliquat 336 (Methyltricaprylammonium chloride), a quaternary amine, is a mixture of $\mathrm{C}_{8}-\mathrm{C}_{10}$ with a minimum assay of $80 \%$ and with molecular weight of 404.17 and density of $0.888 \mathrm{~g} / \mathrm{cm}^{3}$. Caproic acid (99\%) (SD. Fine Chem. Ltd., India) and the diluents methylisobutylketon (MIBK), and xylene (supplied by Qualigens Fine Chemicals, India) are of technical grade and were used without pretreatment. Distilled water was used to prepare the solutions of various concentrations of caproic acid solutions. $\mathrm{NaOH}$ used for the titration is of analytical grade and was supplied by S.D. Fine-Chem. Ltd., India. For the standardization of the $\mathrm{NaOH}$, oxalic acid (99.8\%) was obtained from S.D. Fine-Chem. Ltd, India. Phenolphthalein solution ( $\mathrm{pH}$ range 8.2 - 10.0) was used as indicator for titration and was obtained from S.D. Fine-Chem. Ltd., India. The range of $\mathrm{pH}$ for the experiment was 2.403 3.084 at temperature $301 \mathrm{~K}$. The initial Aliquat-336 concentrations of 0.44 and $0.88 \mathrm{~mol} \cdot \mathrm{L}^{-1}$ and the initial aqueous acid concentration range of $0.005 \mathrm{~mol} \cdot \mathrm{L}^{-1}$ to $0.057 \mathrm{~mol} \cdot \mathrm{L}^{-1}$ were used. Low concentration was used because caproic acid concentration in the fermentation broth is not greater than $0.057 \mathrm{kmol} / \mathrm{m}^{3}$.

\subsection{Methods}

The extraction experiments were performed using a temperature-controlled water bath shaker (Remi Equipment Pvt. Ltd., India) at constant temperature (301 K). Equal volumes $\left(15 \mathrm{~cm}^{3}\right)$ of aqueous and organic phases were taken in a $100 \mathrm{~mL}$ conical flask and were shaken for $12 \mathrm{~h}$. This could be considered as the appropriate time for attaining equilibrium. The solutions were then made to settle for at least $2 \mathrm{~h}$ at a fixed temperature (301 $\mathrm{K}$ ) and atmospheric pressure in a separating funnel. The lower phase was taken for analysis after filtration through the MILLEX GV filter unit $(0.22 \mu \mathrm{m})$. Aqueous phase $\mathrm{pH}$ was measured by a digital $\mathrm{pH}$ meter (Superfit, India). The aqueous phase acid concentration was determined by titration with $\mathrm{NaOH}$. The results of the above methods were noted when $\mathrm{NaOH}$ is prepared fresh every time before titration was to be carried out. The acid content in the organic phase was determined by material balance. The few experiments were repeated to check the consis- 
tency and found within limit of $\pm 2 \%$.

\section{Results and Discussions}

The extraction equilibria of caproic acid by xylene and MIBK (physical) and extractant-diluent combinations (chemical) were studied. The physical extraction using xylene and MIBK is shown in Figure 2. The regression equations for the physical extraction equilibrium of caproic acid in the two diluents is represented as

$[\mathrm{HA}]_{\text {org }}=3172[\mathrm{HA}]_{\mathrm{aq}}^{2}+0.504[\mathrm{HA}]_{\mathrm{aq}}$ for xylene (11)

$[\mathrm{HA}]_{\mathrm{org}}=37506[\mathrm{HA}]_{\mathrm{aq}}^{2}+4.209[\mathrm{HA}]_{\mathrm{aq}} \quad$ for MIBK (12)

The coefficient of $[\mathrm{HA}]^{2}$ and $[\mathrm{HA}]_{\mathrm{aq}}$ provides the values of dimerization constant and partition coefficient, respectively, for the respective extractions. In all the cases the extraction was good with the $K_{\mathrm{D}}$ (ratio of total acid concentration in organic phase to total acid in aqueous phase) value lying between 3.39 - 13.5 and 13.5 - 48 for xylene and MIBK, respectively, for the various initial concentrations of caproic acid in aqueous phase. The degree of extraction is in the range of $77 \%-93 \%$ and $93 \%-98 \%$ in xylene and MIBK, respectively. Extraction of caproic acid in xylene is low as compared to MIBK.

Tables 1 and 2 demonstrate the influence of the organic solvent and the organic phase concentration of Aliquat 336 on the distribution coefficient of caproic acid in xylene and MIBK respectively. Aliquat 336 concentration 0.44 and $0.88 \mathrm{kmol} / \mathrm{m}^{3}$ was used in diluents for the acid concentrations of $0.005,0.01,0.02,0.03$, 0.04 and $0.0572 \mathrm{kmol} / \mathrm{m}^{3}$. The function of diluent is to dilute the extractant to the desired concentration and controls the viscosity and density of the solvent phase.
The Aliquat 336 concentration was not used above $40 \%$ because usually it was found that the $K_{\mathrm{D}}$ decreases with the increase of the Aliquat 336 content was accompanied with the viscosity increase of the system also, which causes the problem of Aliquat 336 to disengage. Further the extraction involving Aliquat 336, higher initial acid concentrations and the increase of the Aliquat 336 content also pose the problem of third phase formation.

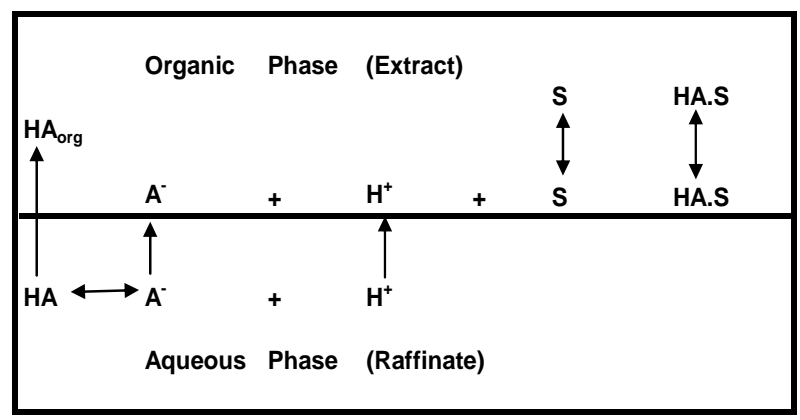

Figure 1. Mechanism for the reactive extraction of caproic acid (HA).

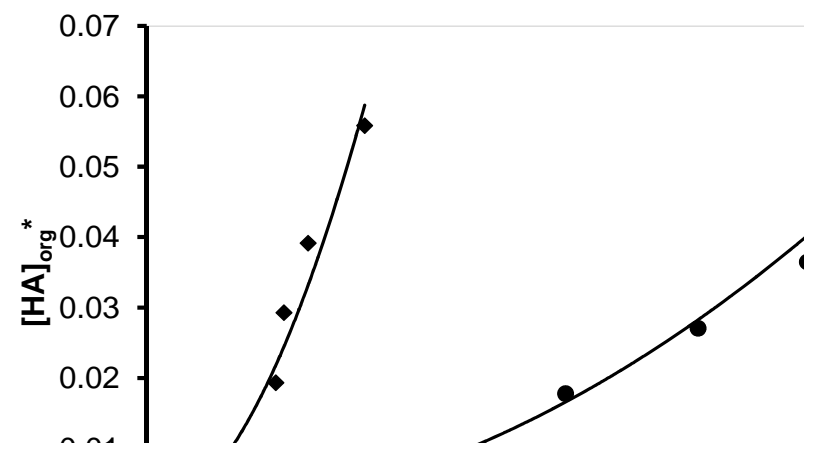

Figure 2. Physical extraction of caproic acid (HA) in xylene and MIBK.

Table 1. Extraction equilibrium results for Aliquat 336/xylene/caproic acid system at $301 \mathrm{~K}$ for the various concentrations of Aliquat $\mathbf{3 3 6}$ and acid.

\begin{tabular}{|c|c|c|c|c|c|}
\hline Initial acid conc. $\left(\mathrm{kmol} \cdot \mathrm{m}^{-3}\right)$ & Extractant Conc. $\left(\mathrm{kmol} \cdot \mathrm{m}^{-3}\right)$ & $\mathbf{p H}_{\mathrm{eq}}$ & $K_{\mathrm{D}}$ & $E(\%)$ & $Z_{t}$ \\
\hline \multirow{2}{*}{0.057} & 0.44 & 2.467 & 12.8 & 92.75 & 0.1202 \\
\hline & 0.88 & 2.464 & 12.6 & 92.66 & 0.06 \\
\hline \multirow{2}{*}{0.04} & 0.44 & 2.503 & 10.4 & 91.22 & 0.0829 \\
\hline & 0.88 & 2.481 & 9.33 & 90.32 & 0.0411 \\
\hline \multirow{2}{*}{0.03} & 0.44 & 2.547 & 9.38 & 90.36 & 0.0616 \\
\hline & 0.88 & 2.5 & 7.42 & 88.13 & 0.03 \\
\hline \multirow{2}{*}{0.02} & 0.44 & 2.56 & 6.31 & 86.32 & 0.0392 \\
\hline & 0.88 & 2.52 & 5.15 & 83.74 & 0.019 \\
\hline \multirow{2}{*}{0.01} & 0.44 & 2.573 & 2.87 & 74.19 & 0.0169 \\
\hline & 0.88 & 2.539 & 2.34 & 70.06 & 0.008 \\
\hline \multirow{2}{*}{0.005} & 0.44 & 2.583 & 1.02 & 50.44 & 0.0057 \\
\hline & 0.88 & 2.551 & 0.76 & 43.21 & 0.0025 \\
\hline
\end{tabular}


Table 2. Extraction equilibrium results for Aliquat 336/MIBK/caproic acid system at $301 \mathrm{~K}$ for the various concentrations of Aliquat 336 and acid.

\begin{tabular}{|c|c|c|c|c|c|}
\hline Initial PA conc. $\left(\mathrm{kmol} \cdot \mathrm{m}^{-3}\right)$ & Extractant Conc. $\left(\mathrm{kmol} \cdot \mathrm{m}^{-3}\right)$ & $\mathbf{p H}_{\mathrm{eq}}$ & $K_{\mathrm{D}}$ & $E(\%)$ & $Z_{t}$ \\
\hline \multirow{2}{*}{0.057} & 0.44 & 2.496 & 14.8 & 93.66 & 0.1213 \\
\hline & 0.88 & 2.361 & 7.49 & 88.22 & 0.0571 \\
\hline \multirow{2}{*}{0.04} & 0.44 & 2.517 & 11.1 & 91.74 & 0.0834 \\
\hline & 0.88 & 2.403 & 6.24 & 86.19 & 0.0392 \\
\hline \multirow{2}{*}{0.03} & 0.44 & 2.535 & 8.85 & 89.85 & 0.0613 \\
\hline & 0.88 & 2.436 & 5.32 & 84.17 & 0.0287 \\
\hline \multirow{2}{*}{0.02} & 0.44 & 2.547 & 5.92 & 85.54 & 0.0389 \\
\hline & 0.88 & 2.472 & 3.97 & 79.86 & 0.0182 \\
\hline \multirow{2}{*}{0.01} & 0.44 & 2.56 & 2.65 & 72.64 & 0.0165 \\
\hline & 0.88 & 2.503 & 1.85 & 64.89 & 0.0074 \\
\hline \multirow{2}{*}{0.005} & 0.44 & 2.569 & 0.9 & 47.34 & 0.0054 \\
\hline & 0.88 & 2.531 & 0.61 & 38.05 & 0.0022 \\
\hline
\end{tabular}

The $K_{\mathrm{D}}$ values for Aliquat 336 in xylene lies in the range of 0.76 - 12.8 (Table 1). It was found that increasing the Aliquat 336 content in the organic phase decreases the equilibrium concentration of the acid in the organic phase and hence gives the lower distribution. The maximum removal of caproic acid was for 0.057 $\mathrm{kmol} / \mathrm{m}^{3}$ caproic acid solution when MIBK alone was used without Aliquat 336. The chemical equilibrium can be obtained by plot of organic versus aqueous concentrations for different concentrations of Aliquat 336 in diluent. A straight line fit was obtained with slope providing overall $K_{D}$ values for respective Aliquat 336 concentrations. Since the loading ratio in all diluents is less than 0.5, the results of the Equation (8) can be also verified by the plot of following equation:

$$
\frac{Z_{t}}{1-Z_{t}}=K_{S 1}[\mathrm{HA}]_{\mathrm{aq}}
$$

The non-ideal behavior is observed due to the excellent ability of xylene and MIBK as diluents to solvate the caproic acid effectively as compared to the effect of Aliquat 336 content as extractant. Thus no synergic effect was observed of Aliquat 336 as extractant. However, if the diluent is a poor solvating medium for the species formed, the polar complexes tend to form clusters in the organic phase at higher phase loadings in the inert diluents.

Further, the results of reactive extraction of caproic acid using Aliquat 336 in MIBK are given in Table 2. The $K_{\mathrm{D}}$ values for Aliquat 336 in MIBK lies in the range of $0.61-14.8$. It was found that this $K_{\mathrm{D}}$ values are less than the physical extraction $\left(K_{\mathrm{D}}=13.5-48\right)$ of caproic acid using MIBK only. Here, synergic effect of extractant was not observed.

The above behaviors may be attributed to the excellent salvation and extraction ability of xylene and MIBK as solvent or diluent and the hindering physicochemical properties of Aliquat 336 in xylene and MIBK and hence the requirement and possibility of modifiers in Aliquat 336 may further be investigated to see the considerable enhancement effects.

\section{Conclusions}

Physical and reactive extraction of caproic acid using Aliquat 336 in xylene and MIBK were studied and following conclusions were made:

- The distribution coefficient of caproic acid in xylene alone was good and lying between 3.39 - 13.5 with degree of extraction in the range of $77 \%-93 \%$.

- Reactive extraction using Aliquat 336 in xylene does not show any synergetic effect on recovery of caproic acid and distribution coefficient lying between 0.76 12.8 .

- The distribution coefficient of caproic acid in MIBK only was found in the range of 13.5 - 48 with degree of extraction in the range of $93 \%-98 \%$.

- Synergic effect was not observed when Aliquat 336 was used in MIBK.

- MIBK is better solvent than xylene for physical extraction and the only physical extraction with MIBK or xylene is better than reactive extraction with Aliquat 336.

- Further the reactive extraction from model and actual fermentation broth will be carried out.

\section{References}

[1] M. N. Ingale and V. V. Mahajani, "Recovery of Butyric Acid, Valeric Acid, and Caproic Acid (BVC Acids) from an Aqueous Waste Stream Using Tributylphosphate (TBP) 
as an Extractant," S.E.P. Technologies, Vol. 4, No. 4, 1994, pp. 252-257.

[2] O. Weyeneth, "Process for the Production of Synthetic Ester Oil out of Waste Liquor of Caprolactam Plant," Chemical Age of India, Vol. 26, 1975, pp. 321-323.

[3] W. R. Kencaly, Y. Cao and P. J. Weimer, "Production of Caproic Acid by Cocultures of Ruminal Cellulolytic Bacteria and Clostridium Kluyveri Grown on Cellulose and Ethanol," Applied Microbiology and Biotechnology, Vol. 44, No. 3-4, 1995, pp. 507-513. doi:10.1007/BF00169952

[4] J. M. Wardell and C. J. King, "Solvent Equilibria for Extraction of Carboxylic Acids from Water," Journal of Chemical \& Engineering Data, Vol. 23, No. 2, 1978, pp. 144-148. doi:10.1021/je60077a009

[5] R. Wennersten, "Extraction of Carboxylic Acid from Fermentation Broth Using Solution of Tertiary Amine," Journal of Chemical Technology \& Biotechnology, Vol. 33-B, 1983, pp. 85-94.

[6] A. S. Kertes and C. J. King, "Extraction Chemistry of Fermentation Product Carboxylic Acids," Biotechnology and Bioengineering, Vol. 28, No. 2, 1986, pp. 269-282. doi:10.1002/bit.260280217

[7] S. T. Yang, S. A. White and S. T. Hsu, "Extraction of Carboxylic Acids with Tertiary and Quaternary Amines," Industrial \& Engineering Chemistry Research, Vol. 30, No. 6, 1991, pp. 1335-1342. doi:10.1021/ie00054a040

[8] C. J. King, "Amine-Based Systems for Carboxylic Acid Recovery: Tertiary Amines and the Proper Choice of Diluent Allow Extraction and Recovery from Water," Chemtech, Vol. 5, 1992, pp. 285-291.

[9] S. Kumar, K. L. Wasewar and B. V. Babu, "Intensification of Nicotinic Acid Separation using Organophosphorous Solvating Extractants by Reactive Extraction," Chemical Engineering and Technology, Vol. 31, No. 11, 2008, pp. 1584-1590. doi:10.1002/ceat.200800245

[10] A. Keshav and K. L. Wasewar, "Back Extraction of Proponic Acid from Loaded Organic Phase," Chemical Engineering Science, Vol. 65, No. 9, 2010, pp. 2751-2757. doi:10.1016/j.ces.2010.01.010

[11] A. Keshav, K. L Wasewar and S. Chand, "Reactive Extraction of Propionic Acid Using Tri-n-octylamine," Chemical Engineering Communications, Vol. 197, 2010, pp. 606-626. doi:10.1080/00986440903249015

[12] A. Keshav, K. L Wasewar and S. Chand, "Extraction of Propionic Acid from Model Solutions: Effect of $\mathrm{pH}$, Salts, Substrate, and Temperature," AIChE Journal, Vol. 55, No. 7, 2009, pp. 1705-1711. doi:10.1002/aic.11780

[13] A. Keshav, K. L Wasewar and S. Chand, "Extraction of Acrylic, Propionic and Butyric Acid Using Aliquat 336 in Oleyl Alcohol: Equilibria and Effect of Temperature,"
Industrial \& Engineering Chemistry Research, Vol. 48, No. 2, 2009, pp. 888-893. doi:10.1021/ie8010337

[14] K. L. Wasewar, A. B. M. Heesink, G. F. Versteeg and V. G. Pangarkar, "Reactive Extraction of Lactic Acid Using Alamine 336 in MIBK: Equilibria and Kinetics," Journal of Biotechnology, Vol. 97, No. 1, 2002, pp. 59-68. doi:10.1016/S0168-1656(02)00057-3

[15] K. L. Wasewar, A. B. M, Heesink, G. F. Versteeg and V. G. Pangarkar, "Equilibria and Kinetics for Reactive Extraction of Lactic Acid Using Alamine 336 in Decanol," Journal of Chemical Technology \& Biotechnology, Vol. 77, No. 9, 2002, pp. 1068-1075. doi:10.1002/jctb.680

[16] K. L. Wasewar, A. Yawalkar, J. Moulijn and V. G. Pangarkar, "Fermentation of Glucose to Lactic Acid Coupled with Reactive Extraction: A Review," Industrial \& Engineering Chemistry Research, Vol. 43, No. 19, 2004, pp. 5969-5982. doi:10.1021/ie049963n

[17] K. L. Wasewar, A. B. M, Heesink, G. F. Versteeg and V. G. Pangarkar, "Intensification of Conversion of Glucose to Lactic Acid: Equilibria and Kinetics for Back Extraction of Lactic Acid Using Trimethylamine," Chemical Engineering Science, Vol. 59, No. 11, 2004, pp. 23152320. doi:10.1016/j.ces.2003.11.023

[18] K. L. Wasewar, "Separation of Lactic Acid: Recent Advances," Chemical and Biochemical Engineering, Vol. 19, No. 2, 2005, pp. 159-172.

[19] H. K. Gaidhani, K. L. Wasewar and V. G. Pangarkar, "Intensification of Enzymatic Hydrolysis of Penicillin-G: 1. Equilibria and Kinetics of Extraction of Phenyl Acetic Acid by Alamine 336," Chemical Engineering Science, Vol. 57, 2002, pp. 1979-1984. doi:10.1016/S0009-2509(02)00078-7

[20] Y. D. Wang, Y. X. Li, Y. Li, J. Y. Wang, Z. Y. Li and Y. Y. Dai, "Extraction Equilibria of Monocarboxylic Acids with Trialkylphosphine Oxide," Journal of Chemical \& Engineering Data, Vol. 46, No. 4, 2001, pp. 831-837. doi: $10.1021 / \mathrm{je} 000381 \mathrm{w}$

[21] M. N. Ingale and V. V. Mahajani, "Recovery of Carboxylic Acids, $\mathrm{C}_{2}-\mathrm{C}_{6}$, from an Stream Using Tributylphosphate (TBP): Effect Aqueous Waste of Presence of Inorganic Acids and Their Sodium Salts," S.E.P. Technologies, Vol. 6, No. 1, 1996, pp. 1-7.

[22] A. Senol, "Liquid-liquid Equilibria for Ternary Systems of (Water + Carboxylic Acid + 1-Octanol) at 293.15 K: Modeling of Phase Equilibria Using a Solvatochromic Approach," Fluid Phase Equilibria, Vol. 227, No. 1, 2005, pp. 87-96. doi:10.1016/i.fluid.2004.10.029

[23] G. Kyuchoukov, M. Marinova, J. Albet and J. Molinier, "New Methods for the Extraction of Lactic Acid by Means of Modified Extractant (Aliquat 336)," Industrial \& Engineering Chemistry Research, Vol. 43, No. 5, 2004, pp. 1179-1184. doi:10.1021/ie030325z 


\section{Nomenclature}

$K_{\mathrm{D}}=$ distribution coefficient

$K_{E}=$ extraction equilibrium constant

[HA $]=$ concentration of acid

$[\mathrm{S}]=$ concentration of extractants

[HA.S] = concentration of acid-extractant complex

$\left[\mathrm{H}^{+}\right]=$concentration of hydroxyl ion

$\left[\mathrm{A}^{-}\right]=$concentration of anion

$\left[\mathrm{mol} / \mathrm{cm}^{3}\right]$ $\left[\mathrm{mol} / \mathrm{cm}^{3}\right]$

$K_{H A}=$ dissociation constant

$E=$ degree of extraction

$\left[\mathrm{cm}^{3} / \mathrm{mol}\right]$

$[-]$
$\mathrm{mol}]$

$Z_{t}=$ loading ratio

\section{Subscripts}

\author{
$\mathrm{aq}=$ aqueous phase \\ org $=$ organic phase \\ $\mathrm{p}=$ solvation number of Aliquat 336
}

$\left[\mathrm{mol} / \mathrm{cm}^{3}\right]$ $\left[\mathrm{cm}^{3} / \mathrm{mol}\right]$

[-]

$[-]$ 